\title{
Low-temperature growth of boron carbide coatings by direct current magnetron sputtering and high-power impulse magnetron sputtering
}

\author{
Susann Schmidt ${ }^{1,2, *}$ (D), Carina Höglund ${ }^{1,2}$, Jens Jensen ${ }^{1}$, Lars Hultman ${ }^{1}$, Jens Birch ${ }^{1}$, \\ and Richard Hall-Wilton ${ }^{2,3}$ \\ ${ }^{1}$ Thin Film Physics Division, Department of Physics, Chemistry and Biology (IFM), Linköping University, SE-581 83 Linköping, \\ Sweden \\ ${ }^{2}$ European Spallation Source ERIC, Tunavägen 24, P. O. Box 176, SE-221 00 Lund, Sweden \\ ${ }^{3}$ Mid-Sweden University, SE-851 70 Sundsvall, Sweden
}

Received: 4 May 2016

Accepted: 26 July 2016

Published online:

1 August 2016

(C) The Author(s) 2016. This article is published with open access at Springerlink.com

\begin{abstract}
$\mathrm{B}_{4} \mathrm{C}$ coatings for ${ }^{10} \mathrm{~B}$-based neutron detector applications were deposited using high-power impulse magnetron sputtering (HiPIMS) and direct current magnetron sputtering (DCMS) processes. The coatings were deposited on $\mathrm{Si}(001)$ as well as on flat and macrostructured (grooved) Al blades in an industrial coating unit using $\mathrm{B}_{4} \mathrm{C}$ compound targets in Ar. The HiPIMS and DCMS processes were conducted at substrate temperatures of 100 and $400{ }^{\circ} \mathrm{C}$ and the Ar pressure was varied between 300 and $800 \mathrm{mPa}$. Neutron detector-relevant coating characterization was performed and the coating properties were evaluated with regard to their growth rate, density, level of impurities, and residual coating stress. The coating properties are mainly influenced by general process parameters such as the Ar pressure and substrate temperature. The deposition mode shows only minor effects on the coating quality and no effects on the step coverage. At a substrate temperature of $100{ }^{\circ} \mathrm{C}$ and an Ar pressure of $800 \mathrm{mPa}$, well-adhering and functional coatings were deposited in both deposition modes; the coatings showed a density of $2.2 \mathrm{~g} / \mathrm{cm}^{3}$, a B/C ratio of $\sim 3.9$, and the lowest compressive residual stresses of $180 \mathrm{MPa}$. The best coating quality was obtained in DCMS mode using an Ar pressure of $300 \mathrm{mPa}$ and a substrate temperature of $400{ }^{\circ} \mathrm{C}$. Such process parameters yielded coatings with a slightly higher density of $2.3 \mathrm{~g} / \mathrm{cm}^{3}$, a B/C ratio of $\sim 4$, and the compressive residual stresses limited to $220 \mathrm{MPa}$.
\end{abstract}

Address correspondence to E-mail: susann.schmidt@liu.se 


\section{Introduction}

The recent intense and focused search for alternatives to ${ }^{3} \mathrm{He}$-based detectors has shown that detectors based on the boron isotope ${ }^{10} \mathrm{~B}$ are feasible alternatives $[1,2]$ both in their performance and economically [3-10]. ${ }^{10} \mathrm{~B}$ has a relatively high neutron absorption cross section compared to ${ }^{3} \mathrm{He}$, and by optimizing the design of the detector, a detection efficiency comparable to ${ }^{3} \mathrm{He}$ has been presented $[3,11]$. When a neutron is absorbed by a ${ }^{10} \mathrm{~B}$ atom, there is a $94 \%$ probability that the nuclear reaction ${ }^{10} \mathrm{~B}+\mathrm{n} \rightarrow{ }^{7} \mathrm{Li}(0.84 \mathrm{MeV})+{ }^{4} \mathrm{He}(1.47 \mathrm{MeV})+\gamma$ $(0.48 \mathrm{MeV})$ takes place, otherwise ${ }^{10} \mathrm{~B}+\mathrm{n} \rightarrow{ }^{7} \mathrm{Li}$ $(1.02 \mathrm{MeV})+{ }^{4} \mathrm{He}(1.78 \mathrm{MeV})$.

For many ${ }^{10} \mathrm{~B}$-based detector applications, ${ }^{10} \mathrm{~B}$ has to be deposited as "high-quality" thin films onto various substrate types. In this case, "high quality" is defined by neutron-hard, well-adhering films of thicknesses $>1 \mu \mathrm{m}$ featuring low residual stresses, maximum amounts of the neutron absorbing element ${ }^{10} \mathrm{~B}$, and thus a minimum of unfavorable impurities like $\mathrm{H}, \mathrm{O}, \mathrm{C}$, and $\mathrm{N}$. The process must also be scalable to several hundred square meters of two-side coated substrates at affordable production prices. Natural boron contains $20 \%{ }^{10} \mathrm{~B}$, but the isotope separation is relatively easy and $>95 \%{ }^{10} \mathrm{~B}$-enriched material is commercially available.

In previous publications [3, 12, 13], direct current magnetron sputtering (DCMS) was shown to provide suitable deposition processes for the production of ${ }^{10} \mathrm{~B}_{4} \mathrm{C}$ large area neutron detectors. ${ }^{10} \mathrm{~B}_{4} \mathrm{C}$ is the preferred material, instead of ${ }^{10} \mathrm{~B},{ }^{10} \mathrm{BN}$, or other ${ }^{10} \mathrm{~B}$ containing compounds, due to its relatively high boron content in combination with excellent wear resistance and thermal and chemical stability [14-17]. Additionally, the radiation hardness has recently been shown to be appropriate for these neutron detector applications [18].

Reference [12] addresses adhesion issues that often arise for micrometer-range-thick $\mathrm{B}_{4} \mathrm{C}$ films due to high residual film stresses in combination with low adhesive forces between the $\mathrm{B}_{4} \mathrm{C}$ film and the substrate. Here, the film adhesion on $\mathrm{Al}$ substrates was reported to improve significantly as elevated substrate temperatures between 300 and $400{ }^{\circ} \mathrm{C}$ are used. However, there is still a need for a well-working process at substrate temperatures below $200{ }^{\circ} \mathrm{C}$, allowing the deposition of adhering, high-quality ${ }^{10} \mathrm{~B}_{4} \mathrm{C}$ coatings on temperature sensitive substrates.
Additionally, the inherently poor step coverage of coatings deposited by DCMS on macrostructured (commonly grooved) Al blades [4] needs further investigation. The poor step coverage arises due to the line-of-sight deposition nature of this technique [19]. As was pointed out by Stefanescu et al., ${ }^{10} \mathrm{~B}_{4} \mathrm{C}$ coating thickness non-uniformity on such macrostructured blades may lead to detector efficiency losses of up to $10 \%$ [20].

A possible solution to the above mentioned concerns, yet still using an industrial-scale magnetron sputtering process, may be high-power impulse magnetron sputtering (HiPIMS). In HiPIMS processes, the flux of ionized target material usually exceeds the flux of ionized working gas [21-25]. This implies not only benefits with regard to the film morphology and density, but also for the residual stress [26, 27] and the step coverage [21]. Although ion bombardment of the growing film has frequently been reported to yield high film stresses [28], the comparison of films deposited by DCMS and HiPIMS showed significantly reduced stresses without sacrificing film hardness or density in case HiPIMS was used [29]. Here, mainly the sputter gas and target material properties, i.e., mass and ionization potentials, together with appropriate bias voltage setting were found decisive.

Therefore, this study explores DCMS and HiPIMS process parameters for the growth of $\mathrm{B}_{4} \mathrm{C}$ coatings on temperature-sensitive or macrostructured substrates. In order to put the quality of coatings deposited using HiPIMS or DCMS at low substrate temperature into perspective, their properties are compared to high-grade coatings deposited by DCMS at elevated substrate temperature. The aim is the deposition of uniform, high-quality $\mathrm{B}_{4} \mathrm{C}$ films onto $\mathrm{Si}$ and various Al substrates with a thickness of $>1 \mu \mathrm{m}$ at low substrate temperatures without adhesion-enhancing interlayers in order to meet the requirements of different ${ }^{10} \mathrm{~B}$-based neutron detector technologies.

\section{Experimental details}

$\mathrm{B}_{4} \mathrm{C}$ films were deposited in an industrial coating unit (CC800/9, CemeCon AG, Germany). A base pressure of less than $0.5 \mathrm{mPa}$ was achieved prior to deposition. The depositions were carried out in DCMS and HiPIMS modes. All coating processes utilized two rectangular $\mathrm{B}_{4} \mathrm{C}$ compound targets with an area of 
$440 \mathrm{~cm}^{2}$. The $\mathrm{B}_{4} \mathrm{C}$ targets were mounted on two, each other facing cathodes and sputtered in $\mathrm{Ar}$ atmosphere.

Prior to deposition, the sputter system was evacuated at full pumping speed for $2 \mathrm{~h}$ and the substrates were degassed at the intended deposition temperature. The deposition of the $\mathrm{B}_{4} \mathrm{C}$ films was conducted at $75 \%$ of the full pumping speed. The influences of the substrate temperature and deposition pressure on the $\mathrm{B}_{4} \mathrm{C}$ coating properties grown in DCMS and HiPIMS modes were investigated. For our experiments, the deposition temperatures of 100 and $400{ }^{\circ} \mathrm{C}$ were chosen. The working gas pressures were adjusted to 300, 450, 600, and $800 \mathrm{mPa}$ by the Ar flow and kept constant throughout the deposition. In DCMS mode, a power of $3500 \mathrm{~W}$ was applied to each cathode. In HiPIMS mode, the same average target power of $3500 \mathrm{~W}$ together with a pulse frequency of $700 \mathrm{~Hz}$ and a pulse width of $200 \mu \mathrm{s}$ was used. The pulse parameters yielded an energy per pulse $\left(\mathrm{E}_{\mathrm{pP}}\right)$ of $5 \mathrm{Ws}$. No additional bias voltage was supplied to the substrate table in both deposition modes in order to reduce residual coating stresses and to provide well-adhering coatings. The floating potential was measured to be approximately $-40 \mathrm{~V}$.

Films with thicknesses between 1.4 and $1.9 \mu \mathrm{m}$ were grown onto $\mathrm{Si}(001)$ wafer pieces, on flat $\mathrm{Al}$ blades (alloy EN AW-5754) [30], and on macrostructured Al blades [20]. The chosen substrates allow for various material analysis techniques and correspond to frequently used substrates in ${ }^{10} \mathrm{~B}$-based neutron detectors. All Al blades were mounted on a sample carousel with a 2-axis planetary rotation for 2-sided deposition. The Si wafer pieces were attached with stainless steel wires to the flat $\mathrm{Al}$ blades and mounted in a similar position as the flat $\mathrm{Al}$ substrates without $\mathrm{Si}$. The macrostructured Al blades were mounted inside the deposition chamber so that the grooves were vertical and rotated around their primary axis using twofold rotation.

Cross-sectional scanning electron microscopy (SEM, LEO 1550 Gemini, Zeiss, Germany) was carried out in order to determine the $\mathrm{B}_{4} \mathrm{C}$ thickness and hence the deposition rates of the sputter processes. The instrument, equipped with an in-lens detector, was operated at an acceleration voltage of $5 \mathrm{kV}$ at a working distance of $\sim 3 \mathrm{~mm}$.

In order to study the thickness uniformity of $\mathrm{B}_{4} \mathrm{C}$ coatings on grooved Al blades, cross-sectional SEM was conducted. For sample preparation, the grooved Al blades were cut perpendicular to the grooves, embedded into Bakelite resin (Polyfast, Struers), and subsequently mirror polished. The above mentioned instrument settings were applied for SEM imaging.

The composition and bonding states of the $\mathrm{B}_{4} \mathrm{C}$ films were examined by $\mathrm{X}$-ray photoelectron spectroscopy (Axis UltraDLD, Kratos Analytical, Manchester, UK) using monochromatic $\mathrm{Al}(\mathrm{K} \alpha)$ X-ray radiation $(\mathrm{h} v=1486.6 \mathrm{eV})$. The base pressure in the analysis chamber during acquisition was less than $1 \times 10^{-7} \mathrm{~Pa}$. The XPS survey spectrum and core-level spectra of the B 1s, Ar 2p, C 1s, and O 1s regions were recorded on the as-received samples and after $\mathrm{Ar}^{+}$ etching with a $4 \mathrm{keV} \mathrm{Ar}^{+}$ion beam. In order to remove the surface oxide layer that is generated upon exposure to air, the $\mathrm{Ar}^{+}$beam was rastered over an area of $3 \times 3 \mathrm{~mm}^{2}$ at an incidence angle of $20^{\circ}$. Automatic charge compensation was applied throughout the acquisition. After subtraction of a Shirley-type background, the compositions were extracted from the core-level spectra obtained from sputter cleaned samples applying elemental cross sections provided by Kratos Analytical.

Isotope-specific compositional analysis was performed with time-of-flight elastic recoil detection analysis (ToF-ERDA), using a $36 \mathrm{MeV}^{127} \mathrm{I}^{9+}$ beam at $66^{\circ}$ incidence and $45^{\circ}$ recoil scattering angle. The recoil energy of each element was converted to relative elemental depth profiles using the CONTES code [31].

The residual stresses in the films were determined by the wafer curvature method assessed by X-ray diffraction (XRD, PANalytical Empyrean) [32]. The diffractometer, equipped with a $\mathrm{Cu} \mathrm{Ka1}$ source, was operated at $45 \mathrm{kV}$ and $40 \mathrm{~mA}$. The Stoney formula for anisotropic single crystal $\mathrm{Si}(001)$ was used to extract residual coating stress from the measured substrate curvature. Here, uniform plane stress in the film was assumed [33]. The same instrument was chosen to study the film density by X-ray reflectivity (XRR). The density was evaluated using the PANalytical $X^{\prime}$ Pert reflectivity software. Here, a 3-layer model, resembling the substrate, the $\mathrm{B}_{4} \mathrm{C}$ films, and a surface oxide layer, was applied.

\section{Results and discussion}

Figure 1a-d presents the cross-sectional SEM images of $\mathrm{B}_{4} \mathrm{C}$ coatings deposited on $\mathrm{Si}(001)$ at a substrate temperature of $400{ }^{\circ} \mathrm{C}$. In Fig. 1a, b, the $\mathrm{B}_{4} \mathrm{C}$ coatings 


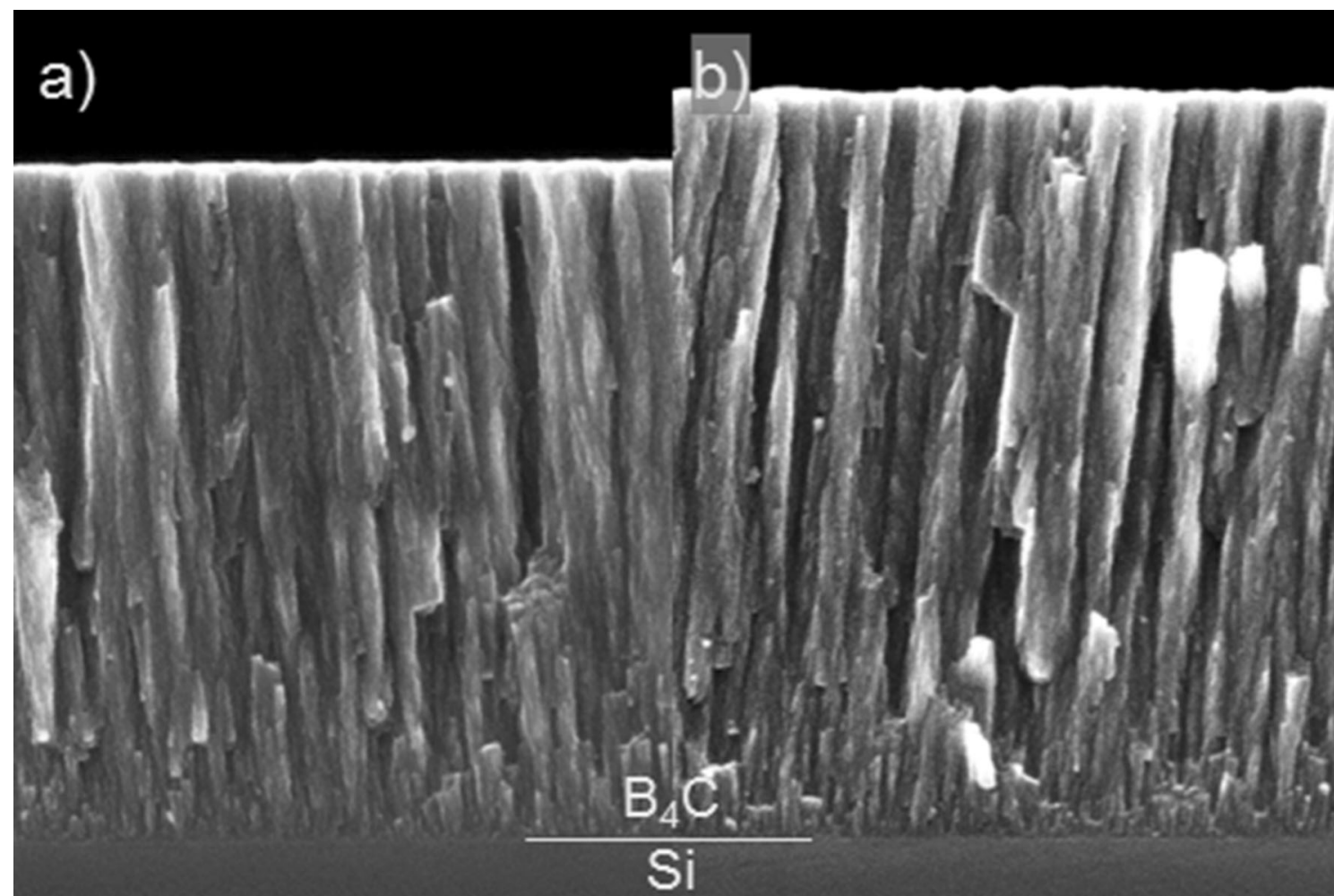

C)
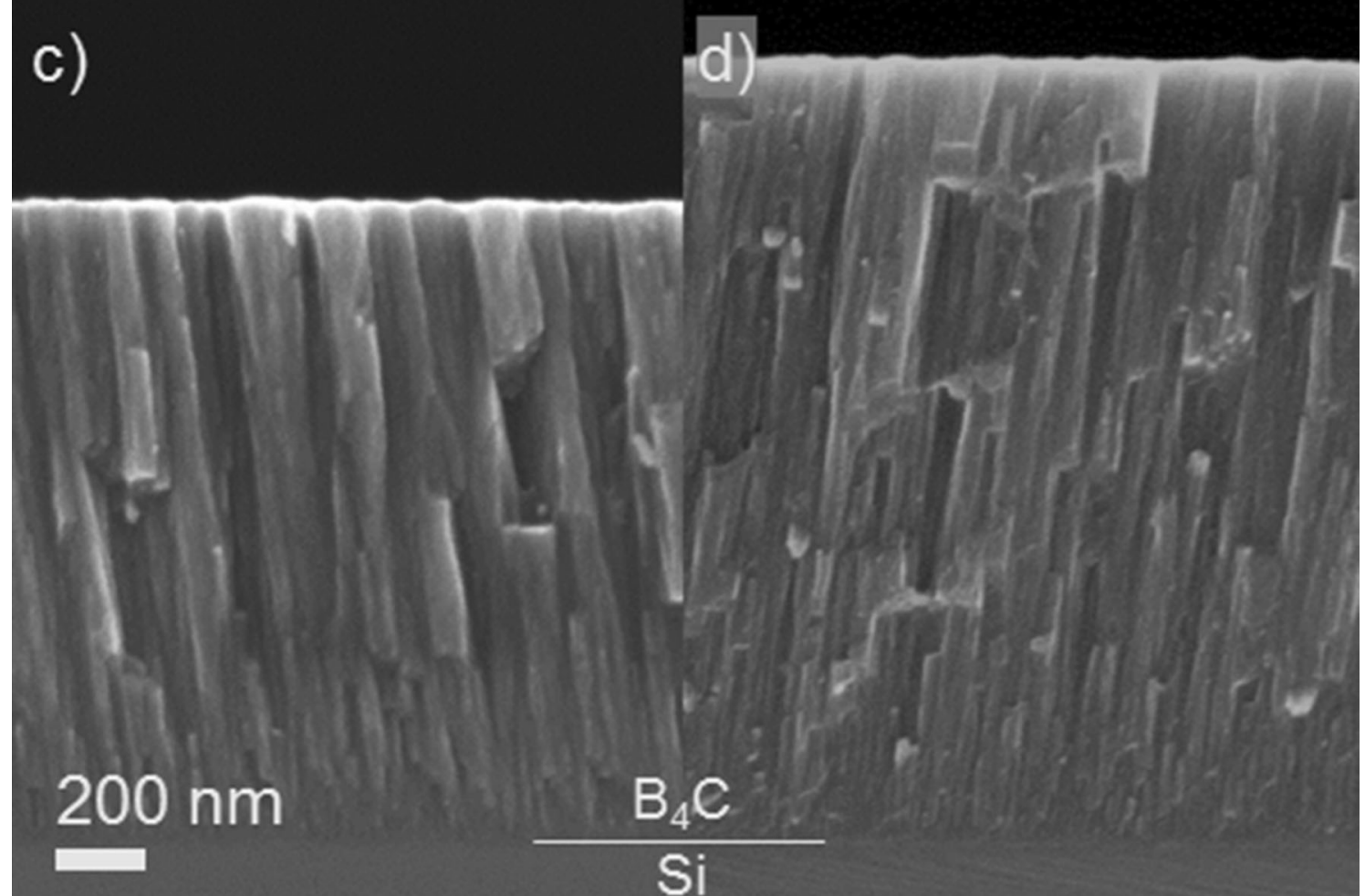

Figure 1 SEM cross-sections of $\mathrm{B}_{4} \mathrm{C}$ coatings deposited on $\mathrm{Si}$ at a substrate temperature of $400{ }^{\circ} \mathrm{C}$ using a DCMS at an Ar pressure of $800 \mathrm{mPa}$, b HiPIMS at $800 \mathrm{mPa}$, c DCMS at $300 \mathrm{mPa}$, and d HiPIMS at $300 \mathrm{mPa}$. The $\mathrm{Si} / \mathrm{B}_{4} \mathrm{C}$ interfaces are indicated. 
were sputtered using an Ar pressure of $800 \mathrm{mPa}$ in DCMS and HiPIMS modes, respectively. Figure 1c, d shows $\mathrm{B}_{4} \mathrm{C}$ coatings deposited at an Ar pressure of $300 \mathrm{mPa}$ using DCMS and HiPIMS, respectively. As can be seen, all samples show columnar morphologies without significant differences. This columnar growth mode is attributed to comparatively low average particle energies and fluxes [34], which is expected for the sputter deposition from $\mathrm{B}_{4} \mathrm{C}$ compound targets and for the chosen bias voltage settings. The flux of sputtered particles is considered to be low due to the comparatively low $\mathrm{B}_{4} \mathrm{C}$ sputter yield of $<0.5$ at/ion at an $\mathrm{Ar}^{+}$energy of $800 \mathrm{eV}$ $[35,36]$. The average particle energy can be estimated to be less than $10 \mathrm{eV}$ on the basis of results in Ref. [29] (cf. Fig. 3a, f black lines in Ref. [29]), given that the peak target currents in the HiPIMS $\mathrm{B}_{4} \mathrm{C}$ processes did not exceed $72 \mathrm{~A}$ and the discharge characteristics of $\mathrm{B}_{4} \mathrm{C}$ were found to be similar to graphite. Moreover, in order to provide well-adhering coatings, the processes were conducted at floating potential, which maintains low particle energies at the growing film surface.

Figure 2 compares the growth rates of DCMS and HiPIMS processes using an average target power per cathode of $3500 \mathrm{~W}$. HiPIMS processes were carried out at a frequency of $700 \mathrm{~Hz}$ yielding an $\mathrm{E}_{\mathrm{pP}}$ of $5 \mathrm{Ws}$. The growth rates for DCMS and HiPIMS processes are comparable, although non-reactive HiPIMS of commonly sputtered metals yields generally lower growth rates compared to DCMS [37]. The reduced growth rate in HiPIMS is mainly attributed to an increased amount of back-attracted ionized species caused by an increased ionization of the sputtered material [38, 39]. In case the $\mathrm{B}_{4} \mathrm{C}$ compound target is operated in HiPIMS mode, an enhanced ionization of sputtered target material is not apparent. We ascribe this to the comparatively high first ionization energies of $B$ and $C$ of 8.3 and $11.26 \mathrm{eV}$, respectively, as well as the low sputter yield of $\mathrm{B}_{4} \mathrm{C}$.

Furthermore, Fig. 2 shows an increasing growth rate as the Ar pressure is raised from 300 to $800 \mathrm{mPa}$. Depending on the pressure, the substrate temperature of $100{ }^{\circ} \mathrm{C}$ yields growth rates between 0.50 and $0.64 \mu \mathrm{m} / \mathrm{h}$, while the growth rates at $400{ }^{\circ} \mathrm{C}$ show slightly reduced values ranging between 0.45 and $0.54 \mu \mathrm{m} / \mathrm{h}$. The drop in deposition rate at elevated temperatures can be attributed to an increased adatom mobility at the growing substrate surface. High ad-atom mobilities increase the probability for

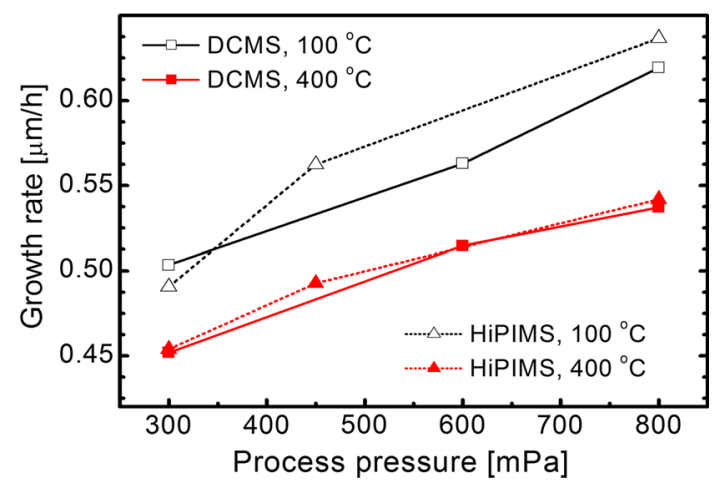

Figure 2 Growth rates as a function of the process pressure for $\mathrm{B}_{4} \mathrm{C}$ coatings deposited at the substrate temperatures of $100{ }^{\circ} \mathrm{C}$ (black) and $400{ }^{\circ} \mathrm{C}$ (red) using DCMS (squares) and HiPIMS (triangles). The estimated uncertainty is less than $\pm 8 \%$.

recombination reactions at the growing film substrate, where volatile species may form [40]. At $T_{\mathrm{s}}=400{ }^{\circ} \mathrm{C}$, this process may be assisted by an elevated desorption of contaminants from the chamber walls. Moreover, the slightly increased densities (cf. discussion on coating densities below and Fig. 4) that were extracted for films deposited at $T_{\mathrm{s}}=400{ }^{\circ} \mathrm{C}$ contribute to reduced growth rates.

The $\mathrm{B}_{4} \mathrm{C}$ coating thickness uniformity on grooved $\mathrm{Al}$ blades of processes conducted at $400{ }^{\circ} \mathrm{C}$ is shown in Fig. 3a. Cross-sectional SEM images were acquired at the top, the slope, and the bottom of the grooves, which have a height of $2.1 \mathrm{~mm}$ and an opening angle of $45^{\circ}[4]$ as depicted in Fig. 3b. As shown in Fig. 3a, the coating thickness uniformity of all investigated processes is neither significantly influenced by the deposition mode nor by the applied Ar pressure. The coating thickness at the slope of the grooves was found to range between 60 and $70 \%$ of the coating thickness at the top, and drops further to values between 23 and $27 \%$ at the bottom. The line-of-sight deposition of magnetron sputtering is well known [19]. Therefore, abruptly decreasing coating thicknesses at the slope and the bottom of the grooves are expected not only in DCMS mode, but also in HiPIMS mode, since an enhanced ionization of sputtered target material is not apparent as outlined above. The step coverage was also shown to be influenced by the particle mean free path, which in turn is affected by the Ar pressure [41-43]. Saito et al. [42] varied the process pressure and demonstrated that a particle mean free path resembling the target-to-substrate distance yielded the best step coverage. In our study, Ar pressures between 500 and $800 \mathrm{mPa}$ result in a 

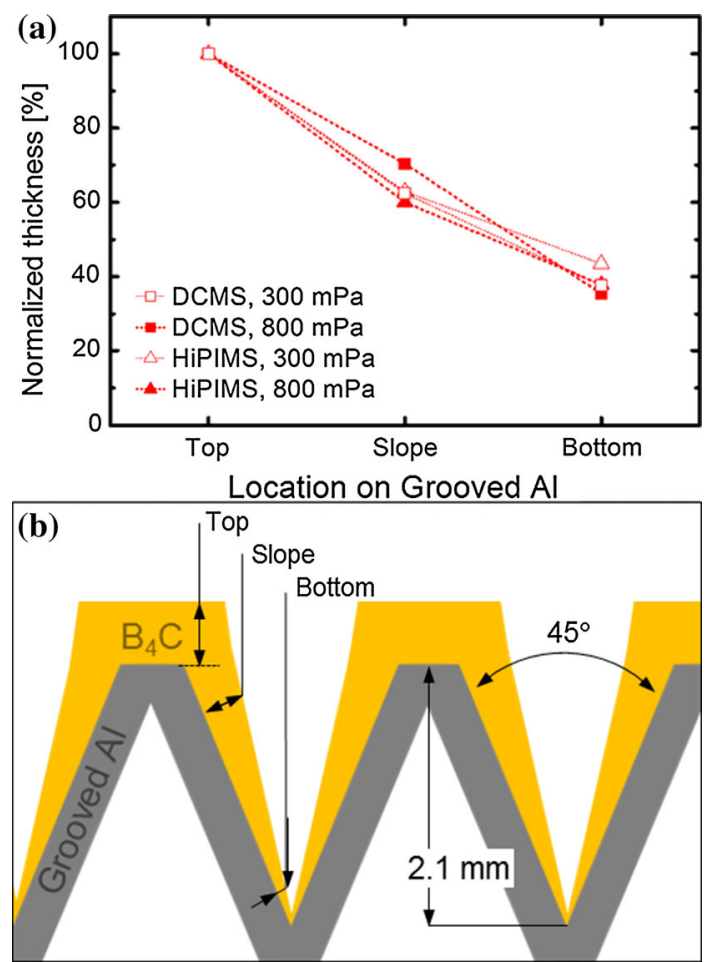

Figure 3 a Normalized $\mathrm{B}_{4} \mathrm{C}$ coating thickness as obtained by SEM cross sections on grooved $\mathrm{Al}$ blades. Images were acquired at the top, slope, and bottom of the grooves as depicted in $\mathbf{b}$ and described in [4]. The coatings were deposited at a substrate temperature of $400{ }^{\circ} \mathrm{C}$. The estimated uncertainty of results shown in $\mathbf{a}$ is $\sim 10 \%$.

particle mean free path of sputtered target material that resembles the actual target-to-substrate distance between $6 \mathrm{~cm}$ and $10 \mathrm{~cm}$ [44] in the twofold rotational setup used for the grooved $\mathrm{Al}$ blades. The fact that the coating uniformities do not differ significantly may be ascribed to the twofold rotation of the grooved blades, which possibly disguises effects induced by the deposition pressure due to shadowing effects.

Figure 4 shows that an elevated substrate temperate of $400{ }^{\circ} \mathrm{C}$ yields $\mathrm{B}_{4} \mathrm{C}$ densities of up to $2.30 \mathrm{~g} / \mathrm{cm}^{3}$ in both deposition modes. Throughout the investigated range of Ar pressures, HiPIMS yields constant film densities of $2.23 \pm 0.02$ and $2.30 \pm 0.01 \mathrm{~g} / \mathrm{cm}^{3}$ at the substrate temperatures of 100 and $400{ }^{\circ} \mathrm{C}$, respectively. The density of films deposited in DCMS mode appears to be affected by pressure. Here, an Ar pressure of $800 \mathrm{mPa}$ results in decreased $\mathrm{B}_{4} \mathrm{C}$ densities of 2.10 and $2.23 \mathrm{~g} / \mathrm{cm}^{3}$ at $T_{\mathrm{s}}=100$ and $400{ }^{\circ} \mathrm{C}$, respectively. Increasing $\mathrm{B}_{4} \mathrm{C}$ densities approaching the $\mathrm{B}_{4} \mathrm{C}$ bulk density of $2.52 \mathrm{~g} / \mathrm{cm}^{3}$ at an elevated

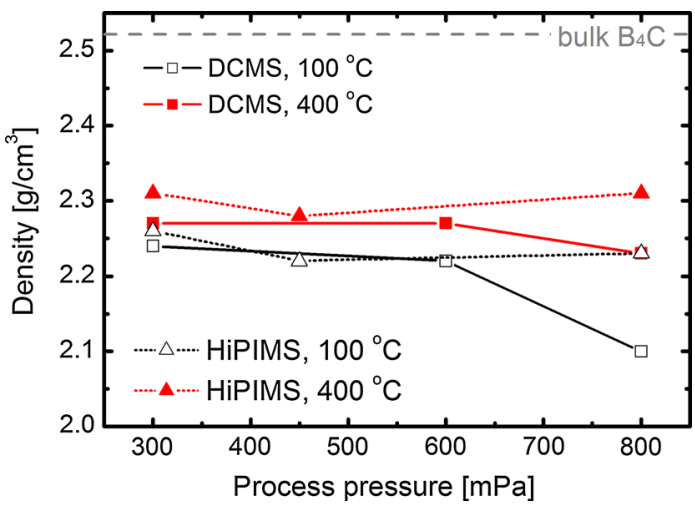

Figure $4 \mathrm{~B}_{4} \mathrm{C}$ coating density over the process pressure for coatings deposited at the substrate temperatures of $100{ }^{\circ} \mathrm{C}$ (black) and $400{ }^{\circ} \mathrm{C}$ (red) using DCMS (squares) and HiPIMS (triangles). The uncertainty of the presented data is less than $\pm 4 \%$.

substrate temperature are a result of the above mentioned increased ad-atom mobility and lower contents of incorporated contaminates like $\mathrm{O}$.

The O-contents and $\mathrm{B} / \mathrm{C}$ ratios presented in Fig. $5 a, b$, respectively, were assessed by XPS measurements after Ar-ion cleaning. As shown in Fig. 5a, the O-content of the coatings is mainly influenced by the Ar pressure and the substrate temperature. The deposition mode affects the O-content only at the pressures of 600 and $800 \mathrm{mPa}$ using a substrate temperature of $100{ }^{\circ} \mathrm{C}$, where the highest $\mathrm{O}$-contents of 5.7 and 6.3 at.\%, respectively, were recorded for $\mathrm{B}_{4} \mathrm{C}$ coating grown in HiPIMS mode. The same process parameters applied in DCMS mode yield $\mathrm{B}_{4} \mathrm{C}$ coatings with the O-contents of 4.6 at. $\%(600 \mathrm{mPa})$ and 5.7 at.\% $(800 \mathrm{mPa})$. Such elevated levels of $\mathrm{O}$ in coatings deposited using HiPIMS are attributed to comparatively long pulse-off times of $1.2 \mathrm{~ms}$, during which $\mathrm{O}$ from the residual gas can attach to the target and the growing film surface. The increase in film O-contents with the Ar pressure is attributed to decreased particle energies caused by an increased probability of particle collisions. At pressures of $600 \mathrm{mPa}$ and above, the average particle mean free path is estimated to be $\sim 6 \mathrm{~cm}$ using the approach proposed in [44]. This suggests that sputtered particles undergo one collision, which leads to reduced particle energies. The increased probability of collisions increases also the probability of reactions with the background gas. Moreover, lowered particle energies inhibit re-sputtering of $\mathrm{O}$ at the growing film surface. As the substrate temperature rises to $400{ }^{\circ} \mathrm{C}$, the ad-atom mobility rises and the desorption of 


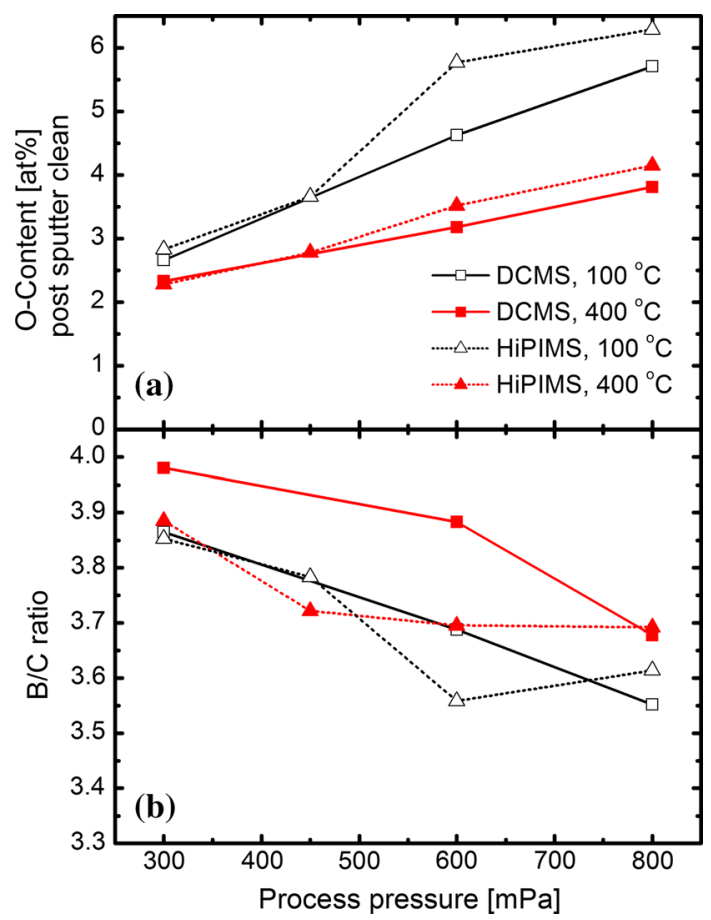

Figure 5 a O-contents and $\mathbf{b} \mathrm{B} / \mathrm{C}$ ratios as obtained by XPS measurements over the process pressure for $\mathrm{B}_{4} \mathrm{C}$ coatings deposited at the substrate temperatures of $100{ }^{\circ} \mathrm{C}$ (black) and $400{ }^{\circ} \mathrm{C}$ (red) using DCMS (squares) and HiPIMS (triangles). For data presented in a, the uncertainty is estimated to be less than $\pm 5 \%$.

O-containing species is catalyzed, which is mirrored in lower O-contents but also lowered growth rates (cf. Figs. 2, 5a).

As presented in Fig. 5b, the films deposited in DCMS mode using a low Ar pressure of $300 \mathrm{mPa}$ and a substrate temperature of $400{ }^{\circ} \mathrm{C}$ show the highest $\mathrm{B} / \mathrm{C}$ ratio of $\sim 4.0$. The same conditions in HiPIMS mode yield films with a decreased $\mathrm{B} / \mathrm{C}$ ratio of $\sim 3.9$. At a substrate temperature of $100{ }^{\circ} \mathrm{C}$, increasing pressures from 300 to $800 \mathrm{mPa}$ result also in decreased $\mathrm{B} / \mathrm{C}$ ratios. The results are directly related to the above discussed $\mathrm{O}$-contents as well as $\mathrm{C}$ contamination from the background and ambient gas.

Figure $6 \mathrm{a}, \mathrm{b}$ shows the compositional depth profiles as obtained by ToF-ERDA of $\mathrm{B}_{4} \mathrm{C}$ films deposited by DCMS and HiPIMS, respectively, at $T_{\mathrm{s}}=400{ }^{\circ} \mathrm{C}$ and an Ar pressure of $300 \mathrm{mPa}$. The results suggest slightly higher levels of $\mathrm{H}, \mathrm{O}$, and $\mathrm{N}$ of the coating deposited in DCMS mode, while the $\mathrm{B} / \mathrm{C}$ ratios of both coatings are comparable with the values of 4.77 and 4.74 for $\mathrm{B}_{4} \mathrm{C}$ films sputtered in DCMS and HiPIMS mode, respectively. The total amount of the

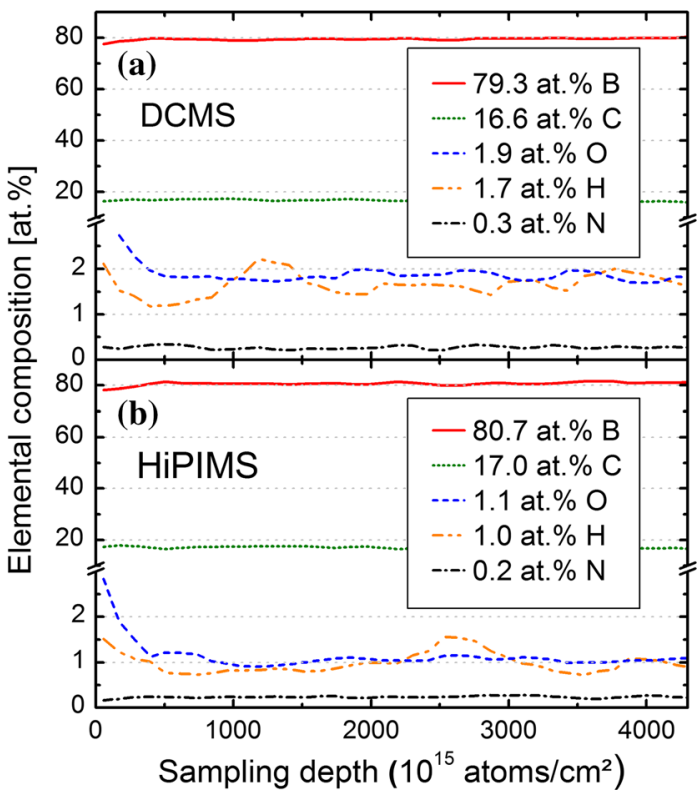

Figure 6 ToF-ERDA depth profiles for $\mathrm{B}_{4} \mathrm{C}$ coatings deposited at $300 \mathrm{mPa}$ and $400{ }^{\circ} \mathrm{C}$ by a DCMS and b HiPIMS. The average elemental composition is indicated for each coating.

impurities $\mathrm{H}, \mathrm{O}$, and $\mathrm{N}$ is 3.9 at.\% for the coating sputtered by DCMS and 2.3 at.\% for the coating grown in HiPIMS mode. The results show also that, apart from the near-surface region, the composition is homogenous for both coatings. The compositions of the near-surface regions of comparable $\mathrm{B}_{4} \mathrm{C}$ coatings were closer, as investigated in [45], where it was shown that surface oxidation extends to a maximum of $60 \mathrm{~nm}$ into the coatings.

Comparing ToF-ERDA and XPS data, the B/C ratios and $\mathrm{O}$-contents are discrepant. This is mainly caused by the surface-sensitive nature of XPS measurements. XPS offers a probing depth of approximately $10 \mathrm{~nm}$ into the coating. Although only data recorded after Ar-ion etching were considered for data evaluation and the base pressure in the analysis chamber during acquisition was less than $1 \times 10^{-7}$ $\mathrm{Pa}$, an overestimation of elements in the background gas, i.e., $\mathrm{O}, \mathrm{C}$, and $\mathrm{N}$, is apparent. Here, surface reactions of the background gas with the Ar-ion etched surface during measurement, residual surface contaminations after Ar-ion etching, or surface contamination that is mixed into the first monolayers of the coating due to the Ar-ion beam may be possible measurement method artifacts. ToF-ERDA data, on the other hand, present the coating composition including $\mathrm{H}$ contents up to a depth of $400 \mathrm{~nm}$ and are 


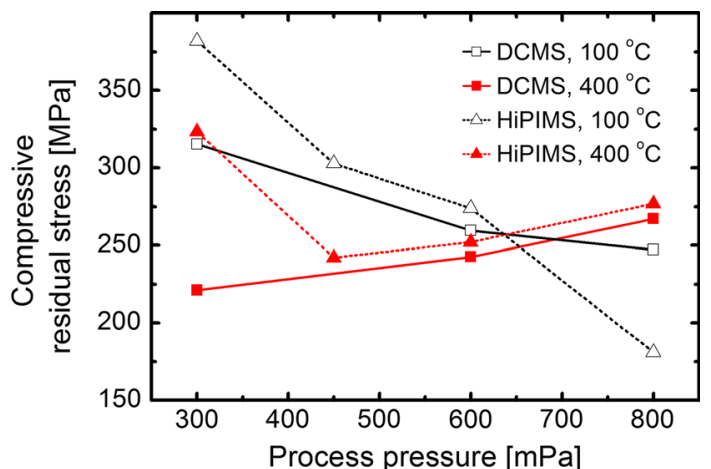

Figure 7 Residual compressive stress over the process pressure for $\mathrm{B}_{4} \mathrm{C}$ coatings deposited at the substrate temperatures of $100{ }^{\circ} \mathrm{C}$ (black) and $400{ }^{\circ} \mathrm{C}$ (red) using DCMS (squares) and HiPIMS (triangles). The uncertainty of the presented data is less than $\pm 8 \%$.

as such considered to mirror the coating composition better.

The compressive residual coating stresses are shown in Fig. 7. Here, the two substrate temperatures induce opposing trends as the pressure increases; at a substrate temperature of $100{ }^{\circ} \mathrm{C}$, the compressive residual coating stress decreases, while the coatings deposited at $400{ }^{\circ} \mathrm{C}$ show increasing compressive stress values. The low-temperature HiPIMS processes span the widest range of stresses throughout the investigated Ar pressure range. While the lowest compressive film stress of $-180 \mathrm{MPa}$ is recorded for $\mathrm{B}_{4} \mathrm{C}$ coatings deposited at a pressure of $800 \mathrm{mPa}$, the highest residual stress of $-380 \mathrm{MPa}$ is obtained using a pressure of $300 \mathrm{mPa}$.

At a substrate temperature of $100{ }^{\circ} \mathrm{C}$, the evolution of the coating stress is mainly attributed to lowered particle energies caused by increased particle scattering as the pressure increases. This, in turn, reduces forward sputtering, which was reported to be one of the major factors that contribute to compressive coating stresses [28]. As mentioned above, the average particle mean free path for collision was estimated to be $\sim 6 \mathrm{~cm}$ at $800 \mathrm{mPa}$, while the collision mean free path increases to $\sim 9$ and $\sim 15 \mathrm{~cm}$ at 450 and $300 \mathrm{mPa}$, respectively [44].

Other commonly reported factors that contribute to increased stress levels in thin films deposited by magnetron sputtering techniques are Ar incorporation and high particle energies. Incorporation of Ar can be excluded here based on its non-existence in ToF-ERDA and XPS measurements of the as-deposited samples. High particle energies arising due to an elevated target mass [46], peak target currents [47], or high bias potentials can also be excluded to contribute to elevated stress levels; HiPIMS processes conducted at 300 and $800 \mathrm{mPa}$ showed comparable and low peak target currents of 68 and 69 A, respectively. Energetic, reflected Ar neutrals are also expected to play a minor role considering the low target/Ar gas mass ratio. Finally, our study was conducted at floating potential where ionized plasma species experience merely a potential drop of less than $40 \mathrm{~V}$.

As the substrate temperature rises to $400{ }^{\circ} \mathrm{C}$, the extracted compressive coating stresses are attenuated, where the values vary within $100 \mathrm{MPa}$ over the investigated range of Ar pressures. The comparatively low stress levels are due to the low coefficient of thermal expansion (CTE, $\alpha)$ of $\mathrm{Si}\left(\alpha=2.7 \times 10^{-6} \mathrm{~K}^{-1}\right)$ compared to $\mathrm{B}_{4} \mathrm{C}\left(\alpha=5 \times 10^{-6} \mathrm{~K}^{-1}\right)$. Moreover, an increased ad-atom mobility at elevated substrate temperatures contributes to the reduction of intrinsic stresses, which is frequently reported for sputter deposited metallic films [28]. As shown in Fig. 7, this effect is reduced at elevated pressures since the deposition rate increases simultaneously. Similar results were reported by Sun et al. [48].

The level of compressive residual coating stress provides also an indication of the coating adhesion. Although the differences in compressive film stress for $\mathrm{B}_{4} \mathrm{C}$ deposited on $\mathrm{Si}$ substrates do not appear substantial, a slight rise of the film stress is mirrored in a delamination of the $\mathrm{B}_{4} \mathrm{C}$ coatings on $\mathrm{Al}$ substrates. The amplification is caused by the comparatively high coefficient of thermal expansion of $\mathrm{Al}$ $\left(\alpha=22.2 \times 10^{-6} \quad \mathrm{~K}^{-1}\right) \quad$ compared to $\mathrm{B}_{4} \mathrm{C}$ $\left(\alpha=5 \times 10^{-6} \mathrm{~K}^{-1}\right)$ and $\mathrm{Si}\left(\alpha=2.7 \times 10^{-6} \mathrm{~K}^{-1}\right)$.

It should be emphasized that the $\mathrm{B}_{4} \mathrm{C}$ coatings deposited at $100{ }^{\circ} \mathrm{C}$ at $800 \mathrm{mPa}$ and all $\mathrm{B}_{4} \mathrm{C}$ films deposited at $400{ }^{\circ} \mathrm{C}$ showed good long-term adhesion on $\mathrm{Si}$ and $\mathrm{Al}$ substrates. Furthermore, at low deposition temperatures the substrate curvature of the $\mathrm{Al}$ blades was significantly reduced. Hence, the deposition of well-adhering $\mathrm{B}_{4} \mathrm{C}$ coatings on temperature sensitive substrates is successfully conducted using elevated pressures.

\section{Conclusions}

${ }^{10} \mathrm{~B}$-based neutron detectors require $\mathrm{B}_{4} \mathrm{C}$ coatings of thicknesses $>1 \mu \mathrm{m}$ that feature highest possible $\mathrm{B} / \mathrm{C}$ ratios, densities, and low amounts of impurities like $\mathrm{H}$, 
$\mathrm{O}$, and $\mathrm{N}$, as well as adequate adhesion. This study investigated DCMS and HiPIMS process parameters for the growth of $\mathrm{B}_{4} \mathrm{C}$ coatings on temperature-sensitive or macrostructured substrates for neutron detector applications. The quality of coatings deposited using HiPIMS or DCMS at a substrate temperature of $100{ }^{\circ} \mathrm{C}$ was compared to high-grade coatings deposited by DCMS at $400{ }^{\circ} \mathrm{C}$. Provided that optimized sputter parameters are applied, both magnetron sputter modes were shown to yield functional $\mathrm{B}_{4} \mathrm{C}$ coatings.

The coating quality was found to be mainly influenced by the substrate temperature and the $\mathrm{Ar}$ pressure, while the deposition mode influences the coating properties only slightly. Within the investigated range of process settings, a pressure of $300 \mathrm{mPa}$ and a substrate temperature of $400{ }^{\circ} \mathrm{C}$ DCMS were shown to yield the highest coating quality. Under such conditions, coatings with a high $\mathrm{B} / \mathrm{C}$ ratio of $\sim 4$, low residual compressive stresses of $220 \mathrm{MPa}$, a low total amount of impurities of 3.9 at.\%, and a density $>90 \%$ of the $\mathrm{B}_{4} \mathrm{C}$ bulk density, specifically $\sim 2.3 \mathrm{~g} / \mathrm{cm}^{3}$, were deposited.

The study presented moreover the feasibility and limitations of a low-temperature deposition of $\mathrm{B}_{4} \mathrm{C}$ coatings. At a substrate temperate of $100{ }^{\circ} \mathrm{C}$ and a pressure of $800 \mathrm{mPa}$, the coatings deposited using HiPIMS and DCMS show an adequate adhesion due to very low residual compressive stresses of $180 \mathrm{MPa}$, but elevated O-contents of $\sim 6$ at.\% as well as slightly reduced densities of $2.2 \mathrm{~g} / \mathrm{cm}^{3}$. Such low-temperature processes are suited to coat temperature sensitive substrates such as glass-reinforced epoxy laminate sheets.

\section{Acknowledgements}

The work has been partially supported by the BrightnESS Project (Horizon 2020, INFRADEV-3-2015, Grant 676548). J. Birch and L. Hultman are grateful for the support from Knut and Alice Wallenberg's Foundation through the project Grant: "Isotopic Control for Ultimate Material Properties." S. Schmidt acknowledges the support by the Carl Tryggers Foundation for Scientific Research (CTS 14:431).

Open Access This article is distributed under the terms of the Creative Commons Attribution 4.0 International License (http://creativecommons.org/licen ses/by/4.0/), which permits unrestricted use, distribution, and reproduction in any medium, provided you give appropriate credit to the original author(s) and the source, provide a link to the Creative Commons license, and indicate if changes were made.

\section{References}

[1] Zeitelhack K (2012) Search for alternative techniques to helium-3 based detectors for neutron scattering applications. Neutron News 23(4):10-13. doi:10.1080/10448632.2012. 725325

[2] Kouzes RT, Ely JH, Erikson LE, Kernan WJ, Lintereur AT, Siciliano ER, Stephens DL, Stromswold DC, Van Ginhoven RM, Woodring ML (2010) Neutron detection alternatives to ${ }^{3} \mathrm{He}$ for national security applications. Nucl Instrum Methods A 623(3):1035-1045. doi:10.1016/j.nima.2010.08.021

[3] Bigault T, Birch J, Buffet JC, Correa J, Hall-Wilton R, Hultman L, Höglund C, Guérard B, Khaplanov A, Piscitelli F, van Esch P (2012) ${ }^{10} \mathrm{~B}$ multi-grid proportional gas counters for large area thermal neutron detectors. Neutron News 23(4):20-25. doi:10.1080/10448632.2012.725329

[4] Stefanescu I, Abdullahi Y, Birch J, Defendi I, Hall-Wilton R, Höglund C, Hultman L, Zee M, Zeitelhack K (2013) A B-10-based neutron detector with stacked multiwire proportional counters and macrostructured cathodes. J Instrum 8:11. doi:10.1088/1748-0221/8/12/p12003

[5] Modzel G, Henske M, Houben A, Klein M, Köhli M, Lennert P, Meven M, Schmidt CJ, Schmidt U, Schweika W (2014) Absolute efficiency measurements with the ${ }^{10} \mathrm{~B}$ based Jalousie detector. Nucl Instrum Methods A 743:90-95. doi:10.1016/j.nima.2014.01.007

[6] Henske M, Klein M, Köhli M, Lennert P, Modzel G, Schmidt CJ, Schmidt U (2012) The ${ }^{10} \mathrm{~B}$ based Jalousie neutron detector - an alternative for ${ }^{3} \mathrm{He}$ filled position sensitive counter tubes. Nucl Instrum Methods A 686:151-155. doi:10.1016/j.nima.2012.05.075

[7] Lacy JL, Sun L, Athanasiades A, Martin CS, Nguyen R, Lyons TD (2010) Initial performance of large area neutron imager based on boron coated straws. In: IEEE Nuclear Science Symposium Conference Record 30 Oct 2010-6 Nov 2010. pp 1786-1799. doi:10.1109/NSSMIC.2010.5874082

[8] Klein M, Schmidt CJ (2011) CASCADE, neutron detectors for highest count rates in combination with ASIC/FPGA based readout electronics. Nucl Instrum Methods A 628(1):9-18. doi:10.1016/j.nima.2010.06.278

[9] Kirstein O, Hall-Wilton R, Stefanescu I, Etxegarai M, Anastasopoulos M, Fissum K, Gulyachkina A, Höglund C, Imam M, Kanaki K, Khaplanov A, Kittelmann T, Kolya S, Nilsson B, Ortega L, Pfeiffer D, Piscitelli F, Ramos JF, Robinson L, Scherzinger J (2014) Neutron position sensitive detectors for the ESS. arXiv: 1411.6194 
[10] Peggs S (2013) ESS technical design report, ESS 2013-001. ESS technical design report, ESS 2013-001, https://eur opeanspallationsource.se/scientific-technical-documentation

[11] Piscitelli F, Esch PV (2013) Analytical modeling of thin film neutron converters and its application to thermal neutron gas detectors. J Instrum 8(04):P04020

[12] Höglund C, Birch J, Andersen K, Bigault T, Buffet J-C, Correa J, van Esch P, Guerard B, Hall-Wilton R, Jensen J, Khaplanov A, Piscitelli F, Vettier C, Vollenberg W, Hultman $\mathrm{L}$ (2012) $\mathrm{B}_{4} \mathrm{C}$ thin films for neutron detection. J Appl Phys 111(10):104908. doi:10.1063/1.4718573

[13] Nowak G, Störmer M, Becker H-W, Horstmann C, Kampmann R, Höche D, Haese-Seiller M, Moulin J-F, Pomm M, Randau C, Lorenz U, Hall-Wilton R, Müller M, Schreyer A (2015) Boron carbide coatings for neutron detection probed by $x$-rays, ions, and neutrons to determine thin film quality. J Appl Phys 117(3):034901. doi:10.1063/1.4905716

[14] Eckardt T, Bewilogua K, van der Kolk G, Hurkmans T, Trinh $\mathrm{T}$, Fleischer W (2000) Improving tribological properties of sputtered boron carbide coatings by process modifications. Surf Coat Technol 126(1):69-75. doi:10.1016/S02578972(00)00525-9

[15] Riedel R (1994) Novel ultrahard materials. Adv Mater 6(7-8):549-560. doi:10.1002/adma.19940060705

[16] Thévenot F (1990) Boron carbide - a comprehensive review. J Eur Ceram Soc 6(4):205-225. doi:10.1016/0955-2219(90)90048-K

[17] Martinez E, Lousa A, Esteve J (2001) Micromechanical and microtribological properties of $\mathrm{BCN}$ thin films near the $\mathrm{B}_{4} \mathrm{C}$ composition deposited by r.f. magnetron sputtering. Diam Relat Mater 10(9-10):1892-1896. doi:10.1016/S09259635(01)00429-0

[18] Höglund C, Zeitelhack K, Kudejova P, Jensen J, Greczynski G, Lu J, Hultman L, Birch J, Hall-Wilton R (2015) Stability of ${ }^{10} \mathrm{~B}_{4} \mathrm{C}$ thin films under neutron radiation. Radiat Phys Chem 113:14-19. doi:10.1016/j.radphyschem.2015.04.006

[19] Hopwood J (2000) Ionized physical vapor deposition, thin film series. Thin film, vol 27. Academic Press, San Diego

[20] Stefanescu I, Abdullahi Y, Birch J, Defendi I, Hall-Wilton R, Höglund C, Hultman L, Seiler D, Zeitelhack K (2013) Development of a novel macrostructured cathode for largearea neutron detectors based on the B-10-containing solid converter. Nucl Instrum Methods A 727:109-125. doi:10. 1016/j.nima.2013.06.003

[21] Kouznetsov V, Macak K, Schneider JM, Helmersson U, Petrov I (1999) A novel pulsed magnetron sputter technique utilizing very high target power densities. Surf Coat Technol 122(2-3):290-293

[22] Vlcek J, Kudlacek P, Burcalova K, Musil J (2007) Ion flux characteristics in high-power pulsed magnetron sputtering discharges. EPL 77(4):5. doi:10.1209/0295-5075/77/45002
[23] Bohlmark J, Alami J, Christou C, Ehiasarian AP, Helmersson $U$ (2005) Ionization of sputtered metals in high power pulsed magnetron sputtering. J Vac Sci Technol A 23(1):18-22. doi:10.1116/1.1818135

[24] Hecimovic A, Ehiasarian AP (2011) Temporal Evolution of the ion fluxes for various elements in HIPIMS plasma discharge. IEEE Trans Plasma Sci 39(4):1154-1164. doi:10. 1109/tps.2011.2106516

[25] Macák K, Kouznetsov V, Schneider J, Helmersson U, Petrov I (2000) Ionized sputter deposition using an extremely high plasma density pulsed magnetron discharge. J Vac Sci Technol A 18(4):1533-1537. doi:10.1116/1.582380

[26] Ehiasarian AP, Vetushka A, Gonzalvo YA, Sáfrán G, Székely L, Barna PB (2011) Influence of high power impulse magnetron sputtering plasma ionization on the microstructure of TiN thin films. J Appl Phys 109(10):104314. doi:10.1063/1. 3579443

[27] Machunze R, Ehiasarian AP, Tichelaar FD, Janssen G (2009) Stress and texture in HIPIMS TiN thin films. Thin Solid Films 518(5):1561-1565. doi:10.1016/j.tsf.2009.09.069

[28] Windischmann H (1992) Intrinsic stress in sputter deposited thin-films. CRC Crit Rev Sol State 17(6):547-596. doi:10. 1080/10408439208244586

[29] Schmidt S, Czigány Z, Wissting J, Greczynski G, Janzén E, Jensen J, Ivanov IG, Hultman L (2016) A comparative study of direct current magnetron sputtering and high power impulse magnetron sputtering processes for $\mathrm{CN}_{\mathrm{x}}$ thin film growth with different inert gases. Diam Relat Mater 64:13-26. doi:10.1016/j.diamond.2016.01.009

[30] Birch J, Buffet JC, Correa J, van Esch P, Guerard B, HallWilton R, Höglund C, Hultman L, Khaplanov A, Piscitelli F (2013) $\left(\mathrm{B}_{4} \mathrm{C}\right)$-B-10 multi-grid as an alternative to $\mathrm{He}-3$ for large area neutron detectors. IEEE Trans Nucl Sci 60(2):871-878. doi:10.1109/tns.2012.2227798

[31] Janson MS (2004) CONTES conversion of time-energy spectra - a program for ERDA data analysis. Internal Report, Uppsala University

[32] Rosakis AJ, Singh RP, Tsuji Y, Kolawa E, Moore NR Jr (1998) Full field measurements of curvature using coherent gradient sensing: application to thin film characterization. Thin Solid Films 325(1-2):42-54. doi:10.1016/S00406090(98)00432-5

[33] Janssen G, Abdalla MM, van Keulen F, Pujada BR, van Venrooy B (2009) Celebrating the 100th anniversary of the Stoney equation for film stress: developments from polycrystalline steel strips to single crystal silicon wafers. Thin Solid Films 517(6):1858-1867. doi:10.1016/j.tsf.2008.07.014

[34] Anders A (2010) A structure zone diagram including plasma-based deposition and ion etching. Thin Solid Films 518(15):4087-4090. doi:10.1016/j.tsf.2009.10.145 
[35] Ono T, Kawamura T, Ishii K, Yamamura Y (1996) Sputtering yield formula for $\mathrm{B}_{4} \mathrm{C}$ irradiated with monoenergetic ions at normal incidence. J Nucl Mater 232(1):52-58. doi:10. 1016/0022-3115(96)00393-5

[36] Pugacheva TS, Jurabekova FG, Miyagawa Y, Valiev SK (1997) Computer simulation of $\mathrm{SiC}$ and $\mathrm{B}_{4} \mathrm{C}$ sputtering by $\mathrm{Ar}^{+}$and $\mathrm{He}^{+}$ions bombardment. Nucl Instrum Methods B 127-128:260-264. doi:10.1016/S0168-583X(96)00936-6

[37] Samuelsson M, Lundin D, Jensen J, Raadu MA, Gudmundsson JT, Helmersson U (2010) On the film density using high power impulse magnetron sputtering. Surf Coat Technol 205(2):591-596. doi:10.1016/j.surfcoat.2010.07. 041

[38] Brenning N, Huo C, Lundin D, Raadu MA, Vitelaru C, Stancu GD, Minea T, Helmersson U (2012) Understanding deposition rate loss in high power impulse magnetron sputtering: I. Ionization-driven electric fields. Plasma Sources Sci Technol 21(2):9. doi:10.1088/0963-0252/21/2/025005

[39] Anders A (2010) Deposition rates of high power impulse magnetron sputtering: physics and economics. J Vac Sci Technol A 28(4):783-790. doi:10.1116/1.3299267

[40] Roth J (1983) Sputtering by particle bombardment II. Springer, Berlin

[41] Wei TW, Cai J, Wang Q, Hu Y, Wang L, Liu ZY, Wu ZJ (2014) Optimization and evaluation of sputtering barrier/ seed layer in through silicon via for 3-D integration. Tsinghua Sci Technol 19(2):150-160
[42] Saito T, Hashimoto T, Ohashi N, Fujiwara T, Yamaguchi H (2002) Copper wires for high speed logic LSI prepared by low pressure long throw sputtering method. Mater Trans 43(7):1599-1604. doi:10.2320/matertrans.43.1599

[43] Balzer M, Fenker M (2014) Three-dimensional thickness and property distribution of $\mathrm{TiC}$ films deposited by $\mathrm{DC}$ magnetron sputtering and HIPIMS. Surf Coat Technol 250:37-43. doi:10.1016/j.surfcoat.2014.02.011

[44] Depla D, Mahieu S (2010) Reactive sputter deposition. Springer, Berlin. doi:10.1007/978-3-540-76664-3

[45] Piscitelli F, Khaplanov A, Devishvili A, Schmidt S, Höglund C, Birch J, Dennison AJC, Gutfreund P, Hall-Wilton R, Van Esch P (2016) Neutron reflectometry on highly absorbing films and its application to ${ }^{10} \mathrm{~B}_{4} \mathrm{C}$-based neutron detectors. Proc R Soc Lond A Math 472(2185):20150711. doi:10. 1098/rspa.2015.0711

[46] Wehner GK, Anderson GS (1970) The nature of physical sputtering. In: Maissel LI, Glang R (eds) Handbook of thin film technology. McGraw-Hill, New York

[47] Hecimovic A, Burcalova K, Ehiasarian AP (2008) Origins of ion energy distribution function (IEDF) in high power impulse magnetron sputtering (HIPIMS) plasma discharge. J Phys D Appl Phys 41(9):10. doi:10.1088/0022-3727/41/9/ 095203

[48] Sun RC, Tisone TC, Cruzan PD (1975) The origin of internal stress in low-voltage sputtered tungsten films. J Appl Phys 46(1):112-117. doi:10.1063/1.322250 